\title{
Perosomus elumbis em um cordeiro no Brasil
}

\author{
Perosomus elumbis in a sheep in Brazil
}

\section{Márcio Botelho de Castro ${ }^{I}$ Matias Pablo Juan SzabóiI Augusto Ricardo Coelho Moscardini ${ }^{\text {II }}$ José Renato Junqueira Borges ${ }^{\mathrm{IV}}$}

\begin{abstract}
- NOTA-
RESUMO

Perosomus elumbis designa um conjunto raro de anomalias congênitas que primariamente incluem agenesia parcial da medula espinhal e vértebras lombossacrais. $O$ presente relato descreve a ocorrência da enfermidade em um ovino neonato no Brasil.

Palavras-chave: perosomus elumbis, ovino, malformação, mortalidade perinatal.

\section{ABSTRACT}

Perosomus elumbis designates a set of rare abnormal congenital abnormalities that primarily includes partial agenesis of spinal cord and lumbosacral vertebrae. The present paper reports the occurrence of the disease in a neonate sheep in Brazil.

Key words: perosomus elumbis, sheep, malformation, perinatal mortality.

O termo perosomus elumbis designa um conjunto raro de anomalias congênitas, que incluem primariamente agenesia parcial da medula espinhal e vértebras lombossacrais. Ocasionalmente, esta malformação é encontrada em animais domésticos e sua etiologia é desconhecida (JUBB \& HUXTABLE, 1993; JONES, 1999). A enfermidade é descrita principalmente em bovinos (JONES, 1999) e ovinos

(DENNIS, 1975a; DENNIS, 1975b; DENNIS, 1975c). No Brasil, há poucos relatos de sua ocorrência, sendo reportados casos em bezerros da raça holandês pretoe-branco (CASTRO et. al., 2003; GOIOZO et. al., 2005).

Este relato descreve a ocorrência de perosomus elumbis em um cordeiro, fêmea, sem raça definida (SRD), com uma semana de idade, encaminhado ao Hospital Veterinário da Universidade de Franca. Ao exame clínico, observou-se que o animal permanecia em decúbito esternal e apresentava incapacidade de locomoção. Foi constatada ausência de sensibilidade cutânea a partir da região lombar, de tônus muscular na cauda e artrogripose dos membros posteriores (Figura 1). O exame radiográfico demonstrou ausência da coluna vertebral após a décima terceira vértebra torácica (T13) e formação incompleta das vértebras sacrais. Também constatou-se deformidade e diminuição do tamanho da $13^{\mathrm{a}}$ vértebra torácica, com malformação das costelas adjacentes. Para evitar sofrimento desnecessário, o ovino foi eutanasiado utilizando-se aprofundamento anestésico com tiopental sódico a $5 \%$. Na necropsia, os achados clínicos e radiográficos foram confirmados. Observou-se, adicionalmente, que a região pélvica e os membros posteriores apresentavam-se unidos à porção anterior do corpo somente por tecido conjuntivo, tecido muscular atrófico e pele (Figura 2). A medula espinhal e o canal vertebral terminavam na
\end{abstract}

ILaboratório de Patologia Veterinária, Faculdade de Agronomia e Medicina Veterinária (FAV), Universidade de Brasília (UnB), CP 04508, 70910-970, Brasília, DF, Brasil. E-mail: mbcastro@unb.br. Autor para correspondência.

IPatologia Veterinária, Faculdade de Medicina Veterinária (FAMEV), Universidade Federal de Uberlândia, Uberlândia, MG, Brasil.

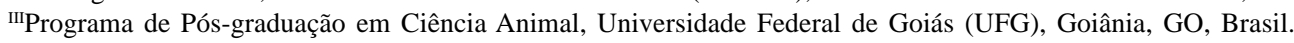

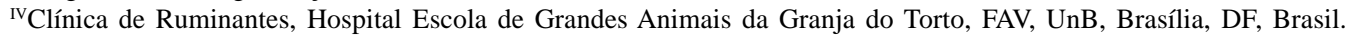




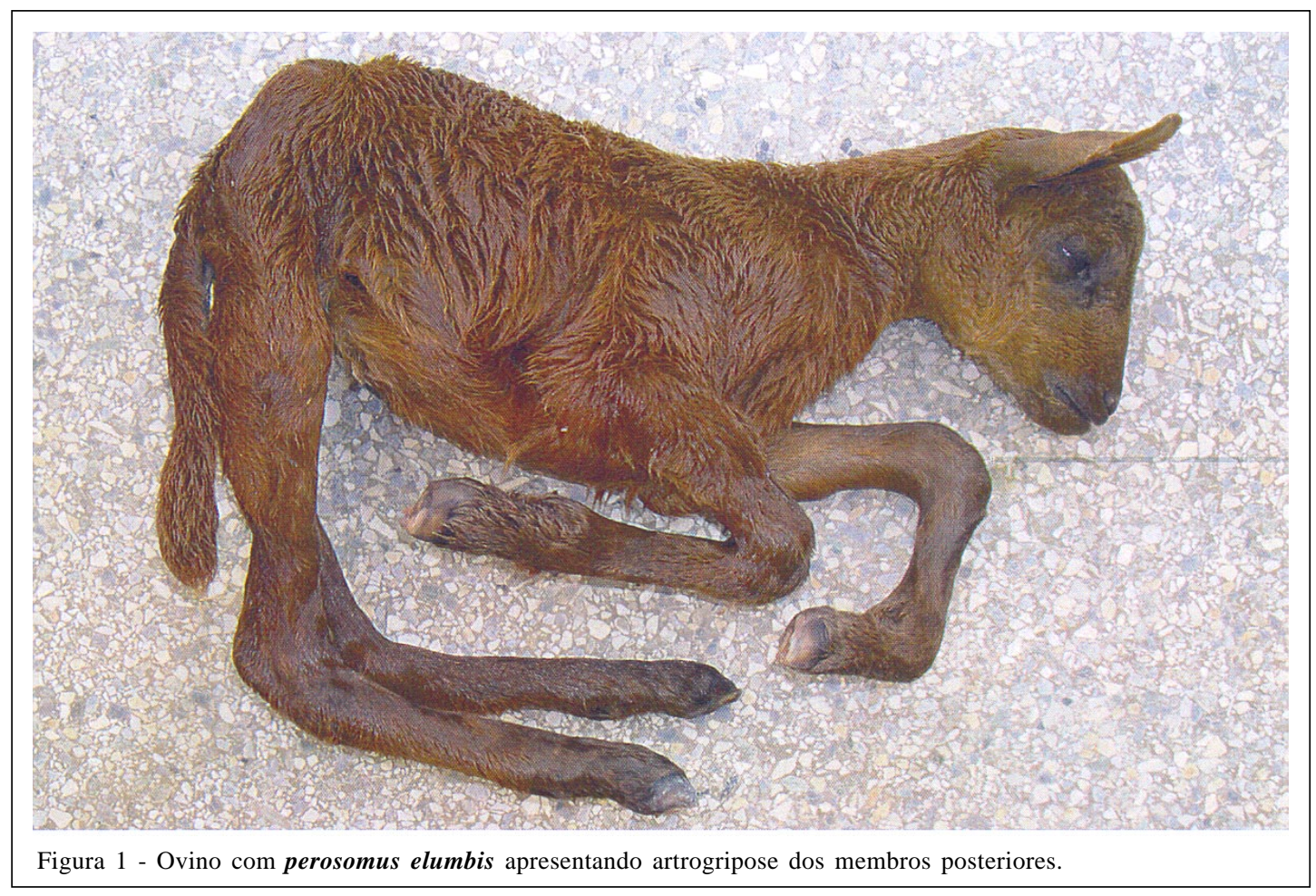

região torácica correspondente (T13), e havia a ausência completa dos arcos vertebrais subseqüentes e da cauda eqüina. A musculatura dos membros posteriores com artrogripose também se apresentava atrófica. Foi constatada a presença de malformação dos ossos pélvicos, com ausência dos ossos púbicos.

A morte perinatal é considerada uma das principais causas de redução da produtividade na ovinocultura (RIET-CORREA \& MÉNDEZ, 2001). Na Austrália, a taxa de mortalidade em cordeiros é de 15 a $20 \%$, ocorrendo a maioria das mortes nos primeiros dias de vida (DENNIS, 1974). No Rio Grande do Sul, estima-se que morrem de 15 a $40 \%$ dos cordeiros nascidos, com aproximadamente 900.000 animais mortos anualmente (FIGUEIRÓ, 1965; MÉNDEZ et al., 1982). DENNIS (1975a), em um levantamento em 4.417 cordeiros com morte perinatal, observou que $9,1 \%$ dos animais apresentavam malformações. No semiárido da Paraíba, a mortalidade perinatal de ovinos é considerada bastante elevada, sendo as malformações uma das principais causas, correspondendo a $23,3 \%$ das perdas. Naquela região, a elevada prevalência de malformações foi atribuída possivelmente à ação teratogênica da planta Mimosa tenuiflora ("juremapreta”), utilizada como forrageira (NÓBREGA et al. 2005). No Rio Grande do Sul, os defeitos congênitos em ovinos apresentam uma importância menor, representando aproximadamente $1 \%$ das mortes (OLIVEIRA \& BARROS, 1982; MÉNDEZ et al., 1982).
As causas que provocam o surgimento do perosomus elumbis em ovinos são praticamente desconhecidas. Na Austrália, porém, atribuiu-se alguns casos a cordeiros nascidos de ovelhas alimentadas com a planta Veratrum californicum entre o $16^{\circ}$ e o $17^{\circ} \mathrm{dia}$ de gestação (DENNIS, 1975b). Neste contexto, merece ainda menção que a infecção pelo vírus de Akabane pode aumentar a prevalência de malformações em ovinos, causando artrogripose e anomalias no sistema nervoso central. A presença do vírus ainda não foi detectada no Brasil (RIET-CORREA \& MÉNDEZ, 2001; SCHMIDT \& OLIVEIRA, 2004). Os mecanismos envolvidos na formação do perosomus elumbis tampouco são conhecidos. Foi sugerido que a migração inadequada do tubo neural, a falha no fechamento do sulco neural e do neuroporo poderiam estar envolvidos com as anomalias, resultando na agenesia parcial da coluna vertebral (HIRAGA\& ABE, 1987; JONES, 1999). A maior parte das malformações vertebrais é resultante de erros na organização do padrão de desenvolvimento e crescimento das células do esclerótomo. A anomalia, no início da segmentação somítica, poderia resultar em malformações esqueléticas e neuromusculares secundárias (NODEN \& de LAHUNTA, 1990). A morfogênese e diferenciação normal devem ser acompanhadas de padrões altamente organizados de expressão e regulação gênica. O processo ontogênico, padrões e suas expressões morfológicas, como a 


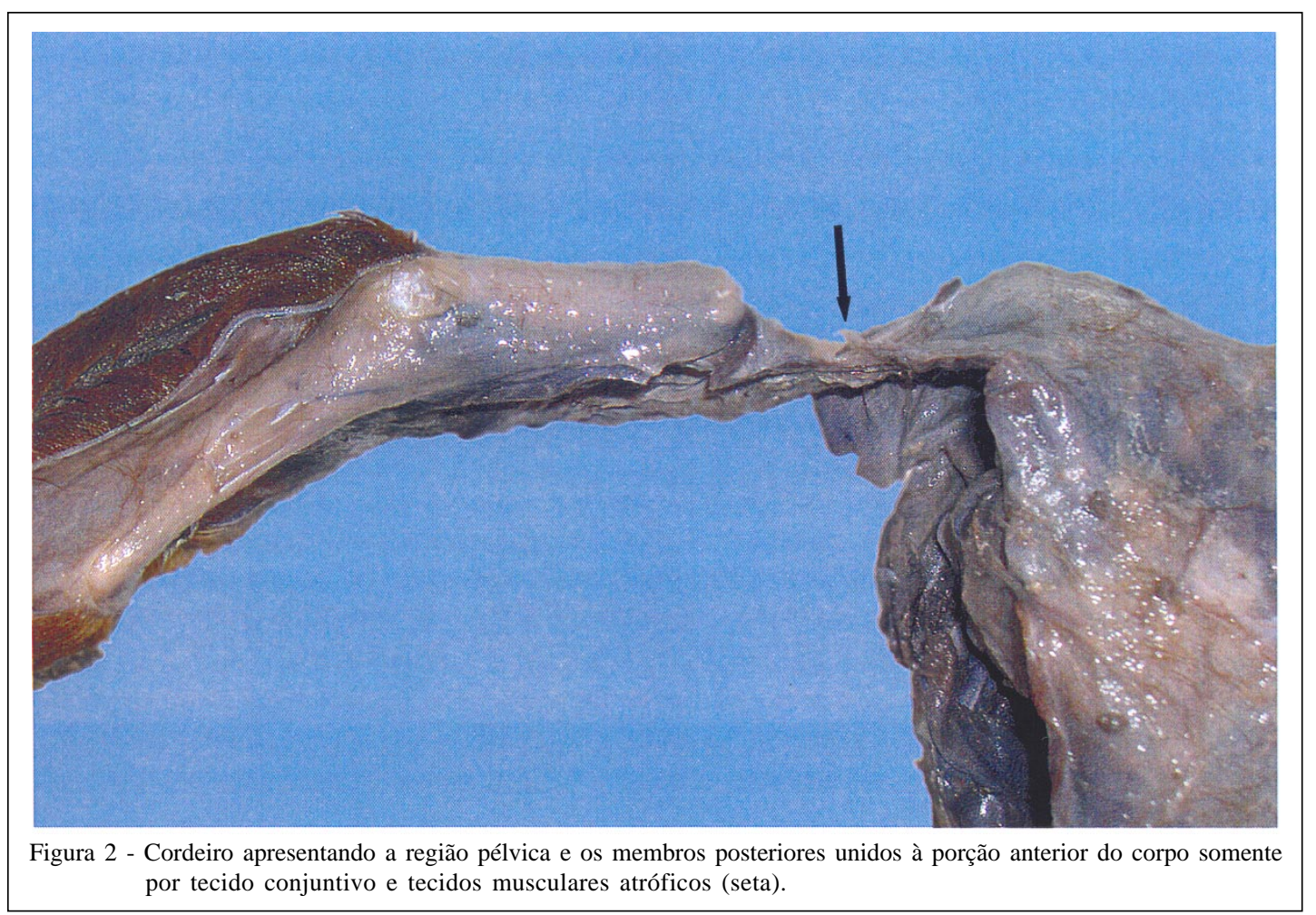

formação do eixo antero-posterior, estão sequencialmente ligados à família do gene homeobox, responsável pela identidade segmentar (NODEN, 1991).

No presente caso, não foi possível detectar ou associar a qualquer agente o surgimento do perosomus elumbis em ovinos. No semi-árido, as malformações em ovinos e caprinos puderam ser associadas, em sua maioria, à ingestão da planta Mimosa tenuiflora. Neste caso, todavia, a ocorrência esporádica em somente um animal, a nãodisponibilidade de plantas tóxicas conhecidamente teratogênicas e o desconhecimento a respeito da participação de agentes infecciosos como causas de malformação não permitem uma conclusão quanto à etiologia. Na ausência de um estudo citogenético, associado ao escasso conhecimento a respeito da embriogênese das malformações em ovinos, apenas especulações poderiam ser feitas a este respeito. A alta freqüência da mortalidade perinatal de ovinos e a escassez de informações a esse respeito no Brasil tornam imprescindíveis o relato e a identificação das causas de mortalidade em cordeiros, em especial, das malformações.

\section{FONTES DE AQUISIÇÃO}

a - Thionenbutal ${ }^{\circledR}$, Abbot Laboratórios do Brasil. São Paulo - SP.

\section{REFERÊNCIAS}

CASTRO, M.B. et al. Perosomus elumbis in a Holstein calf in Brazil. Vet Rec, London, v.152, n.24, p.753, 2003.

DENNIS, S.M. Perinatal lamb mortality in western Australia. Australian Vet J, Sydney, v.50, p.443-449, 1974.

DENNIS, S.M. Perinatal lamb mortality in western Australia: 7. Congenital defect. Australian Vet J, Sydney, v.51, n.2, p.80-82, 1975a.

DENNIS, S.M. Perosomus elumbis in sheep. Australian Vet J, Sydney, v.51, n.3, p.135-136, 1975 b.

DENNIS, S.M. Congenital defects of the nervous system of lambs. Australian Vet J, Sydney, v.51, n.8, p.385-388, 1975c.

FIGUEIRÓ, P. Comunicação pessoal. (Depto de Zootecnia, Univ. Federal de Santa Maria, Santa Maria, Rio Grande do Sul, 1968). In: MÉNDEZ M.C. et. al. Mortalidade perinatal em ovinos nos municípios de Bagé, Pelotas e Santa Vitória do Palmar no Rio Grande do Sul. Pesq Vet Bras, Seropédica, v.2, n.2, p.1-7, 1982.

GOIOZO, P.F.I. et. al. Perosomus elumbis em bovino: relato de caso. Rev Educ Cont CRMV-SP, São Paulo, v.8, n.2, p.164167, 2005.

HIRAGA, T.; ABE, M. Anatomical observation of six calves affected with segmental aplasia of the spinal cord. Anat Record, New York, v.219, n.4, p.402-408, 1987.

Ciência Rural, v.38, n.1, jan-fev, 2008. 
JONES, C.J. Perosomus elumbis (vertebral agenesis and arthrogriposis) in stillborn Holstein calf. Vet Pathol, Washington, v.24, n.1, p.64-70, 1999.

JUBB, K.V.F.; HUXTABLE, C.R. Perosomus elumbis. In: JUBB, K.V.F. et al. (Eds.). Pathology of domestic animals. San Diego: Academic, 1993. V.1, p.276

MÉNDEZ M.C. et. al. Mortalidade perinatal em ovinos nos municípios de Bagé, Pelotas e Santa Vitória do Palmar no Rio Grande do Sul. Pesq Vet Bras, Seropédica, v.2, n.1, p.69-76, 1982

OLIVEIRA, A.C.; BARROS, S.S. Mortalidade perinatal em ovinos no município de Uruguaiana., Rio Grande do Sul. Pesq Vet Bras, Seropédica, v.2, n.1, p.1-7, 1982.

NÓBREGA, J.E. et. al. Mortalidade perinatal de cordeiros no semi-árido da Paraíba. Pesq Vet Bras, Seropédica, v.25, n.3, p.171-187, 2005
NODEN, D.M.; de LAHUNTA, A. Tejidos conectivos y músculos del tronco. In: Embriologia de los animales domésticos. Zaragoza: Acribia, 1990. p.153-170.

NODEN, D.M. Vertebrate craniofacial development: the relation between ontogenetic process and morphological outcome. Brain Behav Evol, Basel, v.38, n.4-5, p.190-225, 1991.

RIET-CORREA, F; MÉNDEZ, M.C. Mortalidade perinatal em ovinos. In: RIET-CORREA et. al. Doenças de ruminantes e equinos. 2.ed. São Paulo: Varela, 2001. v.2, p.417-425.

SCHIMIDT, V.; OLIVEIRA, R.T. Artrogripose em caprino: Relato de caso. Arq Bras Med Vet Zootec, Belo Horizonte, v.56, n.4, p.438-440, 2004. 